based on scans acquired at rest, our model is blind to different strategies that are chosen by the participants in performing a given task. We refer to these features as "inherent," but we acknowledge that these can be "structurally inherent" (related to brain organization and connectivity) or "functionally inherent" (related to the cognitive state of subjects during the resting-state scan).

The idea that brain connectivity can predict activation has previously been reported for different modalities (22), where diffusion MRI tractography was used (23) to measure connectivity. This study was limited to a specific cognitive task and a predefined anatomical region. More recently, resting-state connectivity has been shown to be predictive of subjects' identity, in a way similar to a fingerprint (24). Rather than simply identifying subjects, our goal was to predict the entire layout of brain activity for each subject. Moreover, we also aim to predict such layout of activity in a number of different cognitive domains, from a single task-free scan, including in subjects that show patterns of activation that are different from the group average (perhaps most strikingly in right-lateralized subjects when the majority of training subjects are left-lateralized).

There are important practical implications of the proposed framework in basic research and translational neuroscience. It provides a method for inferring multiple individualized functional localizers based on a single resting-state scan. Such a tool could be used to investigate in detail the response profiles of localized brain regions without the need to acquire often time-consuming task localizers. Such a tool, if generalizable beyond the young, healthy population that makes up the HCP database, could be used to investigate functional regions in subjects who cannot perform tasks, such as infants or paralyzed patients.

\section{REFERENCES AND NOTES}

1. M. Jenkinson, S. Smith, Med. Image Anal. 5, 143-156 (2001).

2. J. Besle, R. M. Sánchez-Panchuelo, R. Bowtell, S. Francis, D. Schluppeck, J. Neurophysiol. 109, 2293-2305 (2013).

3. F. McNab, T. Klingberg, Nat. Neurosci. 11, 103-107 (2008).

4. I. Mukai et al., J. Neurosci. 27, 11401-11411 (2007).

5. S. M. Tom, C. R. Fox, C. Trepel, R. A. Poldrack, Science 315 , 515-518 (2007).

6. G. S. Wig et al., Proc. Natl. Acad. Sci. U.S.A. 105, 18555-18560 (2008).

7. R. Kanai, G. Rees, Nat. Rev. Neurosci. 12, 231-242 (2011).

8. T. E. Behrens, H. Johansen-Berg, Philos. Trans. R. Soc. Lond. B Biol. Sci. 360, 903-911 (2005).

9. R. E. Passingham, K. E. Stephan, R. Kötter, Nat. Rev. Neurosci. 3. 606-616 (2002)

10. B. T. T. Yeo et al., J. Neurophysiol. 106, 1125-1165 (2011).

11. S. M. Smith et al., Proc. Natl. Acad. Sci. U.S.A. 106, 13040-13045 (2009).

12. D. C. Van Essen et al., Neuroimage 80, 62-79 (2013).

13. D. M. Barch et al., Neuroimage 80, 169-189 (2013).

14. B. Fischl et al., Cereb. Cortex 18, 1973-1980 (2008)

15. T. J. Andrews, S. D. Halpern, D. Purves, J. Neurosci. 17 , 2859-2868 (1997).
16. S. Knecht et al., Brain 123, 74-81 (2000)

17. M. Thiebaut de Schotten et al., Science 309, 2226-2228 (2005)

18. M. W. Cole, D. S. Bassett, J. D. Power, T. S. Braver,

S. E. Petersen, Neuron 83, 238-251 (2014)

19. E. C. Robinson et al., Neuroimage 100, 414-426 (2014).

20. N. K. Logothetis, B. A. Wandell, Annu. Rev. Physiol. 66 , 735-769 (2004)

21. K. J. Friston, Brain Connect. 1, 13-36 (2011).

22. Z. M. Saygin et al., Nat. Neurosci. 15, 321-327 (2012)

23. P. J. Basser, S. Pajevic, C. Pierpaoli, J. Duda, A. Aldroubi, Magn Reson. Med. 44, 625-632 (2000)

24. E. S. Finn et al., Nat. Neurosci. 18, 1664-1671 (2015)

\section{ACKNOWLEDGMENTS}

Data were provided by the Human Connectome Project, WU-Minn Consortium (Principal Investigators: D. Van Essen and K. Uğurbil; 1U54MH091657) funded by the $16 \mathrm{NIH}$ Institutes and Centers that support the NIH Blueprint for Neuroscience Research; and by the McDonnell Center for Systems Neuroscience at Washington University in St. Louis. The data are available for download at www. humanconnectome.org. Data from the Q3 release (Septembe 2013) were used in this paper. All code available upon request from the corresponding author. Funding was provided by the U.K. Medical Research Council (MR/L009013/1 to S.J.), U.K. Engineering and Physical Sciences Research Council (EP/L023067/1 to S.J. and T.E.B.), James S. McDonnell Foundation (JSMF220020372 to T.E.B.), the Wellcome Trust (WT104765MA to T.E.B. and 098369/Z/12/Z to S.M.S.), and the Netherlands Organization for Scientific Research (NWO) (452-13015 to R.B.M.). Author contributions were as follows: S.J. and I.T. built the model and performed the analyses. S.J., I.T., R.B.M., O.P.J., S.M.S., and T.E.B. wrote the paper.

\section{SUPPLEMENTARY MATERIALS}

www.sciencemag.org/content/352/6282/216/suppl/DC1

Materials and Methods

Figs. S1 to S23

Tables S1 to S3

Captions for Movies S1 to S7

References (25-38)

Movies S1 to S7

5 November 2015; accepted 29 February 2016

10.1126/science.aad8127

POLITICAL SCIENCE

\title{
Durably reducing transphobia: A field experiment on door-to-door canvassing
}

\author{
David Broockman ${ }^{1 *}$ and Joshua Kalla ${ }^{2}$
}

Existing research depicts intergroup prejudices as deeply ingrained, requiring intense intervention to lastingly reduce. Here, we show that a single approximately 10 -minute conversation encouraging actively taking the perspective of others can markedly reduce prejudice for at least 3 months. We illustrate this potential with a door-to-door canvassing intervention in South Florida targeting antitransgender prejudice. Despite declines in homophobia, transphobia remains pervasive. For the intervention, 56 canvassers went door to door encouraging active perspective-taking with 501 voters at voters' doorsteps. A randomized trial found that these conversations substantially reduced transphobia, with decreases greater than Americans' average decrease in homophobia from 1998 to 2012. These effects persisted for 3 months, and both transgender and nontransgender canvassers were effective. The intervention also increased support for a nondiscrimination law, even after exposing voters to counterarguments.

ntergroup prejudice, defined broadly as negative attitudes about an outgroup, is a root cause of numerous adverse social, political, and health outcomes (1-3). Influential theories depict intergroup prejudices as deeply ingrained during childhood and highly resistant to change thereafter (4-6). Consistent with these theories, empirical research has found that durably reducing prejudice is challenging. Mass media interventions and other brief stimuli usually fail to reduce prejudiced attitudes (7) or have only temporary effects (8); lasting change ap-

Graduate School of Business, Stanford University, Stanford, CA, USA. ${ }^{2}$ Department of Political Science, University of California, Berkeley, CA, USA.

*Corresponding author. E-mail: dbroockman@stanford.edu pears to require intense intervention over months $(9,10)$. Rare are studies demonstrating prejudicereduction interventions relatively brief in duration yet proven to have lasting effects (4).

Theories of active processing, however, suggest a method for even brief interventions to durably change attitudes. A recurring finding of laboratory studies is that brief messages can durably change individuals' attitudes when individuals engage in active, effortful, processing (known as "System 2" processing) of those messages (11). These studies, conducted on other topics, raise the possibility that brief interventions encouraging active consideration of counter-prejudicial thoughts could produce lasting changes in attitudes toward an outgroup. Perspective-taking, "imagining the world from another's vantage point," is one 
thought process theorized to be especially cognitively active that has been shown to reduce prejudice in laboratory settings $(12,13)$. Together, these theories suggest that an intervention imploring individuals to actively take an outgroup's perspective could durably reduce prejudice. Such an intervention is reported here.

The intervention we report attempted to reduce prejudice toward transgender people, those whose gender identity differs from the sex they were assigned at birth. Prejudice against transgender people (transphobia) is extremely pervasive in the United States, but research on the topic is limited and field studies are scarce (14). However, transphobia is important for at least two reasons. First, reducing transphobia is a recognized public health priority because it puts transgender people at up to 25 times greater risk of abuse, assault, and suicide (14). Attitudes toward transgender people are also of growing political importance. With tolerance toward lesbian, gay, and bisexual (LGB) people increasing, opponents of laws protecting LGB and transgender (LGBT) people from discrimination increasingly promulgate antitransgender stereotypes to build opposition to these laws. For example, a campaign in Houston, Texas, in November 2015 portrayed transgender women as "perverts" who sexually assault young girls in women's restrooms, a strategy that observers believe contributed to voters' rejection of the city's nondiscrimination law (15).

Concerns that opponents of nondiscrimination laws would seek to exacerbate antitransgender prejudice in this manner motivated the intervention we report, door-to-door canvassing conversations in Miami, Florida. In December 2014, the Miami-Dade County Commission passed an ordinance protecting transgender people from discrimination in housing, employment, and public accommodations. Fearing a backlash that might increase transphobia, volunteers and staff from the Los Angeles LGBT Center (www.leadership-lab. org) and SAVE (a South Florida LGBT organization; www.save.lgbt) went door to door to have conversations with Miami-Dade voters.

For the intervention, canvassers first knocked on voters' doors unannounced. The one-time and uninvited nature of this contact method represents a substantial departure from most prejudicereduction efforts previously studied, in which students or employees volunteer to repeatedly interact with teachers or supervisors (4). Canvassers asked to speak with the subject on their list and, once this person's identity was confirmed, identified themselves as volunteers from SAVE. The canvassers then engaged in a series of strategies previously shown to facilitate active processing (11): Canvassers informed voters that they might face a decision about the issue (whether to vote to repeal the law protecting transgender people); canvassers asked voters to explain their views; and canvassers showed a video that presented arguments on both sides. Canvassers also defined the term "transgender" at this point and, if they were transgender themselves, noted this. The canvassers next attempted to encourage "analogic perspectivetaking" (16). Canvassers first asked each voter to talk about a time when they themselves were judged negatively for being different. The canvassers then encouraged voters to see how their own experience offered a window into transgender people's experiences, hoping to facilitate voters' ability to take transgender people's perspectives. The intervention ended with another attempt to encourage active processing by asking voters to describe if and how the exercise changed their mind. The conversations lasted around $10 \mathrm{~min}$ on average. The supplementary materials provide further details.

Like other field studies investigating the effects of brief, psychologically informed interventions $(17,18)$, studying the effects of this intervention sheds light on the efficacy of theories of active

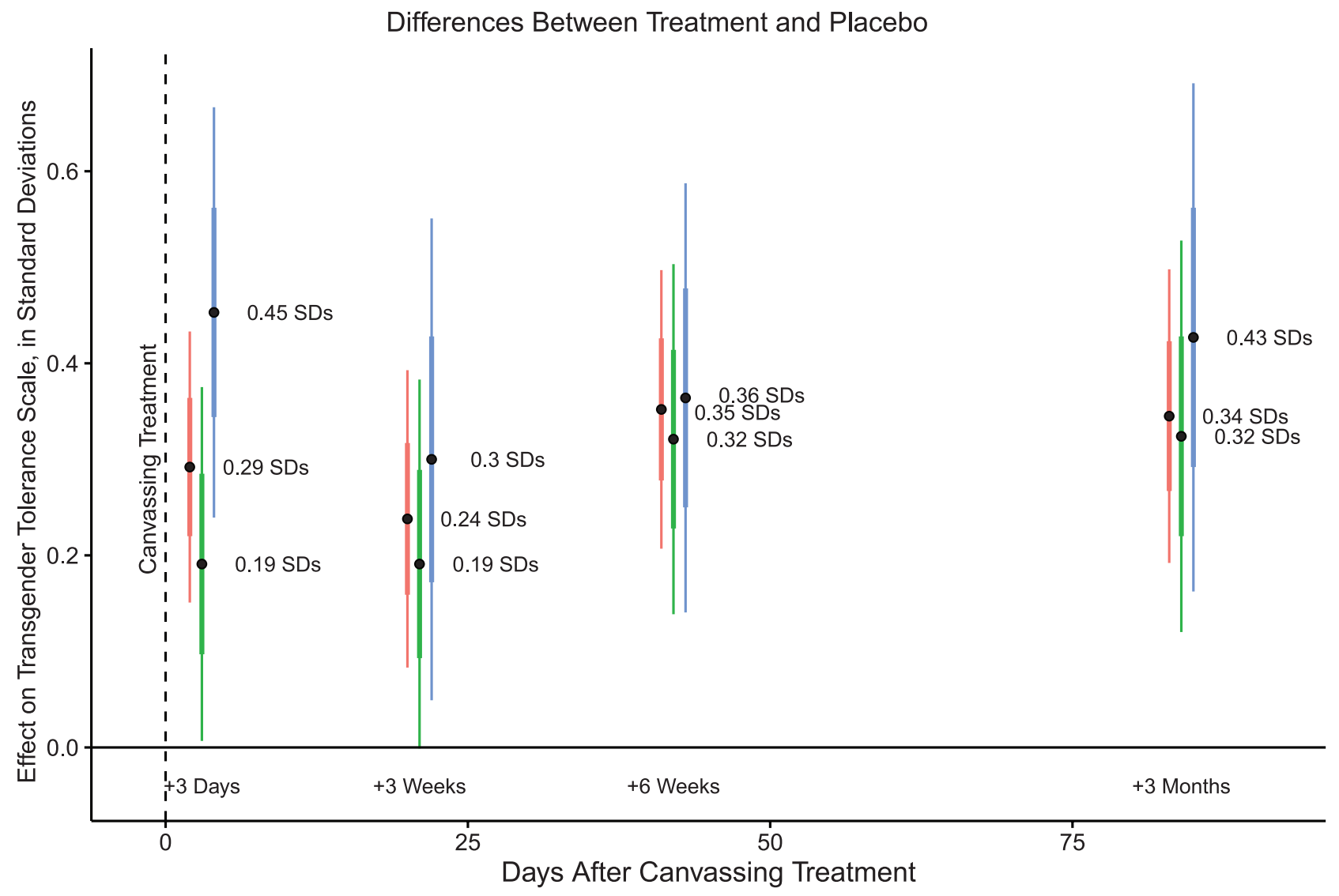

\section{Canvasser || All | Non-Transgender Only | Transgender/Gender}

Fig. 1. Complier average causal effects on transgender tolerance scale. The 95\% confidence intervals surround point estimates; the thicker lines represent one standard error. Both transgender and nontransgender canvassers produced large and lasting increases in tolerance. 
processing and perspective-taking in a field setting. However, this focus on external validity means we cannot be certain that perspective-taking is responsible for any effects or that active processing is responsible for their duration; being primarily concerned with external validity and seeking to limit suspicion, we did not probe intervening processes or restrict the scope of the conversations as a laboratory study would. Nevertheless, as the supplementary materials describe, a majority of the training and conversations focused on encouraging subjects to actively take transgender people's perspectives.

To measure the effects of these conversations, we conducted a randomized placebo-controlled experiment and parallel survey measurement. First, we recruited registered voters $(n=68,378)$ via mail for an ostensibly unrelated online baseline survey, presented as the first in a series of surveys. We next randomly assigned respondents to this baseline survey $(n=1825)$ to either a treatment group targeted with the intervention $(n=913)$ or a placebo group targeted with a conversation about recycling $(n=912)(19)$. Random assignment to treatment or placebo was conducted at the household ( $n=1295)$ level, such that subjects within the same household always had the same treatment assignment. Geographic clusters of respondents were also randomly assigned to have these conversations with canvassers who identified themselves to canvass leaders as transgender $(n=15)$ or as nontransgender $(n=41)$. The intervention then took place as described above;
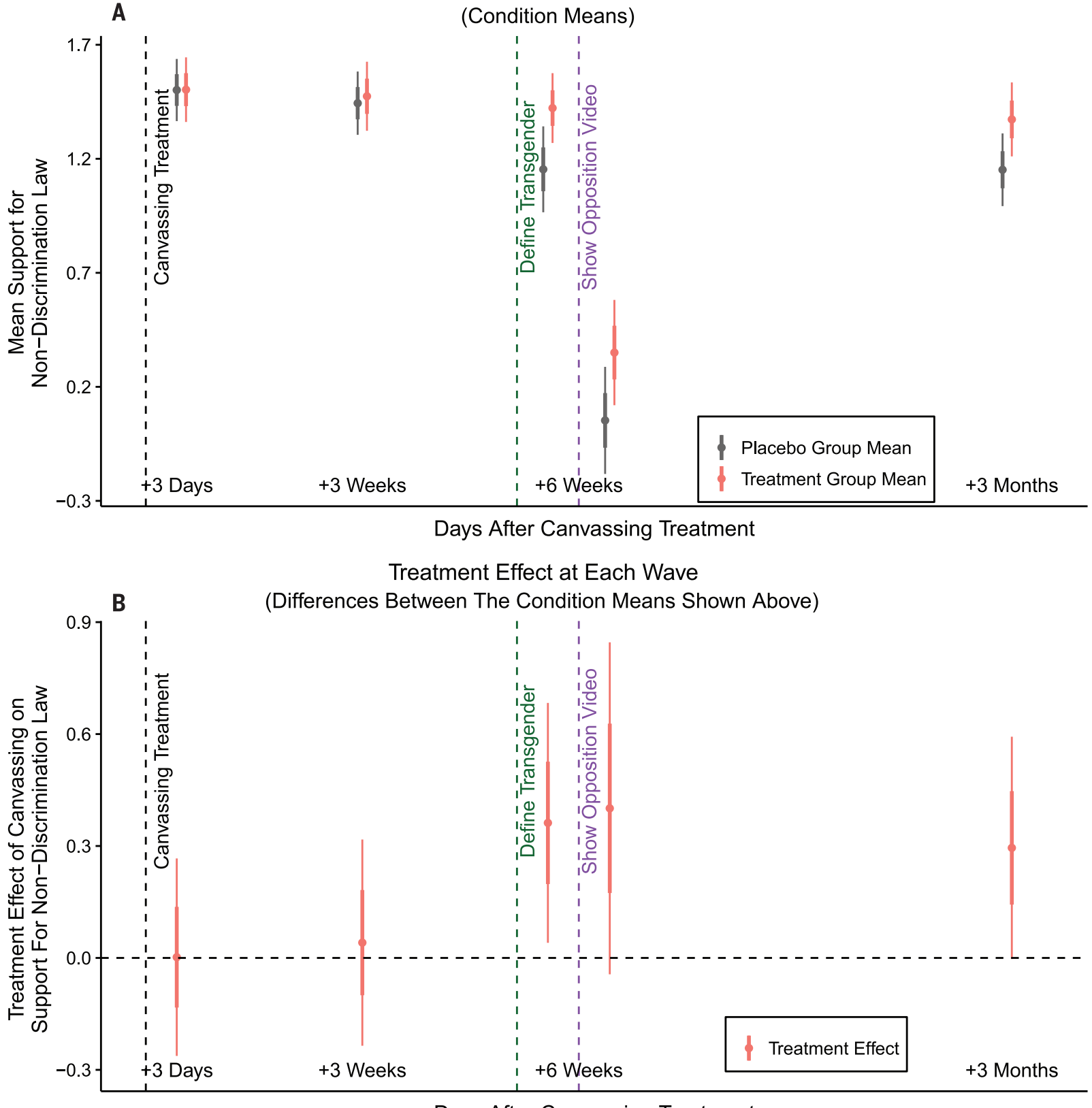

Days After Canvassing Treatment
Support for Non-Discrimination Law (Condition Means)

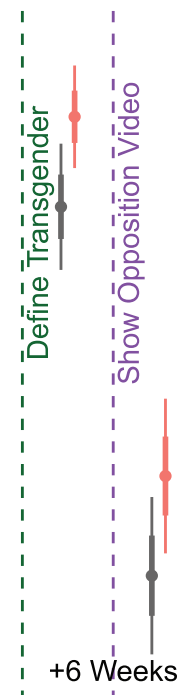

Days After Canvassing Treatment
Placebo Group Mean
Treatment Group Mean +3 Months

Treatment Effect at Each Wave Fig. 2. Support for nondiscrimination law by survey wave. (A) Condition means. (B) Differences between these means. The $95 \%$ confidence intervals
surround point estimates; the thicker lines represent one standard error. Standard errors are adjusted for clustering and pretreatment covariates. Defining Fig. 2. Support for nondiscrimination law by survey wave. (A) Condition means. (B) Differences between these means. The $95 \%$ confidence intervals
surround point estimates; the thicker lines represent one standard error. Standard errors are adjusted for clustering and pretreatment covariates. Defining "transgender" in the item wording revealed that placebo subjects were less supportive of protecting this group $(P<0.05$, one-tailed). Next, all subjects were less supportive after viewing an opposing ad, but the effect of the conversations endured $(P<0.05$, one-tailed). However, the ads' impact dissipated, whereas the conversations' effect endured $(P<0.05$, one-tailed). 
self-identified transgender canvassers revealed their identity to voters during these interactions. Finally, we recruited individuals who came to their doors in either condition $(n=501)$ to complete follow-up online surveys via email presented as a continuation of the baseline survey. These followup surveys began 3 days $(n=429), 3$ weeks $(n=$ 399), 6 weeks $(n=401)$, and 3 months $(n=385)$ after the intervention. See fig. S1 for an overview.

Two survey design features warrant note. First, although transgender rights have gained considerable media attention recently, many other derogatory terms are widely used to refer to this group, and we feared that many subjects would be unfamiliar with the term "transgender." Therefore, survey item wordings generally eschewed the term "transgender." One exception is an item about the law, presenting an issue that we will return to later. Second, in order to conceal its connection with the intervention, the survey was presented as a broad university-sponsored public opinion survey, and each wave included dozens of unrelated items, with only a few concerning transgender people. We carefully monitored responses for suspicion and found none.

The supplementary materials supply further recruitment, design, and estimation details, tests of design assumptions (tables S12 to S19), and representativeness assessments (table S20).

First, results indicate that the intervention was broadly successful at increasing acceptance of transgender people, as measured by an index of relevant items. Before the intervention, the treatment and placebo groups scored similarly on this index (see tables S13 to S17). After the intervention, the treatment group was considerably more accepting of transgender people than the placebo group $(t=4.03 ; P<0.001)$. These effects are substantively large: These brief conversations increased positivity toward transgender people, as measured with a survey tool called a "feeling thermometer" $(20,21)$, by $\sim 10$ points, an amount larger than the average increase in positive affect toward gay men and lesbians among Americans between 1998 and 2012 (8.5 points) (see table S22). Figure 1 shows the point estimates at each wave and reveals that these effects persisted longitudinally: The treatment group remained more accepting in every follow-up survey ( $t$ tests; all $P \mathrm{~s}<0.01$ ). (The point estimates are not strictly comparable over time because respondents and factor loadings change slightly; tables S1 to S4 show estimates for each item at each wave.) The intervention was also broadly effective: The effects are significant at the $P<0.01$ level for both registered Democrats and registered Republicans (see table S6) and for those who began more and less supportive than average ( $t$ tests) (see table S8). Finally, conversations with transgender and nontransgender canvassers were both effective (t tests) (see table S5).

Second, these increases in acceptance of transgender people had ramifications for political attitudes: Treatment subjects were more supportive of the law protecting transgender people from discrimination than placebo subjects once the term "transgender" was defined for all subjects.
Figure 2A shows average support for the law, which was measured on -3 to +3 Likert scales, by condition and survey wave. Figure $2 \mathrm{~B}$ shows the estimated treatment effect by survey wave. As Fig. 2 shows, there was no difference between the treatment and placebo groups' support for a law protecting transgender people from discrimination in the 3-day and 3-week follow-up surveys. As we registered in a preanalysis plan before conducting the 6 -week survey, we suspected that many placebo group subjects did not know what the term "transgender" meant (potentially being more familiar with other, derogatory terms for this group), making them unable to connect any antitransgender attitudes with this question about the law. However, the intervention informed treatment group subjects of the term's definition, just as all subjects might learn the term's definition were a political campaign ongoing. Likewise, views about transgender people might not have been focal for subjects when answering the question, whereas, during recent political campaigns, the inclusion of transgender people in nondiscrimination laws has been strongly emphasized (15). We therefore included a definition of the term "transgender" in the survey questions about the law, starting with the 6 -week survey, clearly defining the term and highlighting transgender people's inclusion in the law. As Fig. 2 shows, treatment subjects were 0.36 scale points more supportive of the law protecting this group than placebo subjects once the survey question defined the term "transgender" $(t=2.20 ; P<0.05)$. This result is among the first experimental demonstrations of political attitudes exhibiting a long-lasting shift in response to persuasive communication (22).

One sign that attitude change is strong is that it persists longitudinally, which we have shown; another is that it withstands attack (11). Attack ads featuring antitransgender stereotypes are another common feature of political campaigns waged in advance of public votes on nondiscrimination laws (15). To examine whether support for the law would withstand such attacks, we showed subjects one of three such ads from recent political campaigns elsewhere, then immediately asked about the law again. Unsurprisingly, both groups were less supportive of the law immediately after viewing an attack ad. However, two patterns qualify the ads' effect. First, the intervention's effect withstood this attack: The canvassing intervention treatment group remained 0.40 scale points more supportive of the law than the placebo group ( $t=1.77 ; P<0.05$, one-tailed). This result stands in contrast to the general pattern that competing messages mute the effect of political communication $(23,24)$ and suggests that the intervention would remain effective in a competitive political environment. Second, the ad's effect faded, whereas the canvassing intervention's effect persisted. When we asked the same question in the 3-month survey, both treatment and placebo subjects returned to their pre-ad attitudes. That the effect of the attack ads appeared to decay rapidly mirrors other research on political television advertising $(22,25)$. However, by contrast, the treatment effect of the canvassing con- versations appeared to persist, because subjects in the canvassing treatment group remained 0.30 scale points more supportive than placebo subjects in the 3-month survey $(t=1.94 ; P<0.05$, onetailed). These results suggest that the canvassing intervention's effects were both lasting and politically relevant.

These findings have importance for a number of theoretical and applied questions. First, in light of influential theories that depict prejudiced attitudes as highly durable and resistant to change (4-7), it is surprising that brief personal interactions with strangers could markedly and enduringly reduce prejudice in a field setting. Rigorous field research has seldom documented brief interventions capable of producing large and lasting reductions in prejudice, leading the present results to represent a rare challenge to these theories.

The success of this approach was not obvious beforehand. Field settings present many barriers to perspective-taking, creating uncertainty about perspective-taking's potential outside the laboratory and making field tests a research priority $(12,26)$. This setting presented further barriers still. Transgender people are extremely stigmatized (14), which could have led individuals to resist imagining transgender people's perspective, especially when a transgender person was present $(13,26)$. That uninvited strangers could durably reduce prejudice when asking individuals to take transgender people's perspective regardless of their own identity is thus particularly auspicious for these theories. However, whether active processing indeed moderates the persistence of perspective-taking's effects is an open question better suited to laboratory research, as is whether "analogic" reflection on one's own personal experiences of stigma facilitates taking the perspective of stigmatized groups.

On an applied level, the findings fill a void by providing prejudice-reduction advocates a feasible and proven strategy. A now-retracted article by LaCour and Green studying canvassing on marriage equality by the same organization, the Los Angeles LGBT Center, appeared in Science last year $(27,28)$. This article "provided a template" for gay rights advocates worldwide before its retraction (29). Several patterns in the present study's data renew confidence that advocates could productively deploy the intervention strategy that we report. The intervention was effective among all prespecified subgroups, including political parties. Canvassers did not require extensive experience. Both first-time and experienced canvassers were effective, and most canvassers continued volunteering after the study concluded, indicating that organizations can develop activists who will work to widely deploy the strategy (30).

With this said, whether these theoretical and applied findings are limited in scope to negative attitudes toward transgender people is an open question that these findings cannot address; even though transgender people are widely stigmatized (14), attitudes toward them may be less entrenched than attitudes toward racial minorities, gays and lesbians, or other outgroups. The 
experiment thus invites replication with other outgroups.

The intervention's durable effect on support for a nondiscrimination law also suggests optimism for the public sphere. Over the past century, political campaigns have increasingly relied on mass communication to reach voters (31). However, facing difficulty persuading a polarizing public with these strategies (22), campaigns increasingly eschew making the case for their positions and instead focus on rousing enthusiasm of voters who already agree with them (32). These shifts undermine basic aspirations for democratic discourse. However, these findings suggest that it may be in campaigns' own best interest to place renewed emphasis on a personal exchange of initially opposing views, even regarding controversial issues and across partisan lines.

\section{REFERENCES AND NOTES}

1. American Psychological Association, Declaration for the UN World Conference Against Racism, Racial Discrimination, Xenophobia, and Related Intolerance (2001; www.apa.org/pi/ oema/programs/racism/apa-delegation-report.pdf).

2. R. D. Enos, Proc. Natl. Acad. Sci. U.S.A. 111, 3699-3704 (2014).

3. T. F. Pettigrew, Annu. Rev. Sociol. 24, 77-103 (1998).

4. E. L. Paluck, D. P. Green, Annu. Rev. Psychol. 60, 339-367 (2009).

5. D. O. Sears, C. L. Funk, J. Polit. 61, 1-28 (1999).

6. M. Tesler, Am. J. Polit. Sci. 59, 806-824 (2015).

7. E. L. Paluck, J. Pers. Soc. Psychol. 96, 574-587 (2009).

8. E. L. Paluck et al., PLOS ONE 10, e0138610 (2015).

9. S. W. Cook, in Nebraska Symposium on Motivation, W. J. Arnold, D. Levine, Eds. (Univ. of Nebraska Press, 1969), pp. 179-236.

10. C. V. Laar, S. Levin, S. Sinclair, J. Sidanius, J. Exp. Soc. Psychol. 41. 329-345 (2005)

11. R. E. Petty, C. P. Haugtvedt, S. M. Smith, in Attitude Strength: Antecedents and Consequences, R. E. Petty, J. A. Krosnick, Eds. (Erlbaum Associates, Mahwah, NJ, 1995), pp. 93-130.

12. G. Ku, C. S. Wang, A. D. Galinsky, Res. Organ. Behav., 10.1016/ riob.2015.07.003 (2015)

13. A. D. Galinsky, G. B. Moskowitz, J. Pers. Soc. Psychol. 78 708-724 (2000)

14. A. R. Flores, Polit. Groups Identities 3, 398-416 (2015).

15. M. Fernandez, A. Blinder, Opponents of Houston rights measure focused on bathrooms, and won, N.Y. Times (4 Nov. 2015); available at www.nytimes.com/2015/11/05/us/ houston-anti-discrimination-bathroom-ordinance.htm (accessed 25 Jan. 2016).

16. H. Gehlbach, M. E. Brinkworth, Teach. Coll. Rec. 114, 226-254 (2012).

17. D. W. Nickerson, T. Rogers, Psychol. Sci. 21, 194-199 (2010).

18. E. J. Finkel, E. B. Slotter, L. B. Luchies, G. M. Walton, J. J. Gross, Psychol. Sci. 24, 1595-1601 (2013).

19. D. W. Nickerson, Polit. Anal. 13, 233-252 (2005).

20. K. Sherrill, PS Polit. Sci. Polit. 29, 469-473 (1996).

21. A. S. Yang, Public Opin. O. 61, 477-507 (1997)

22. A. S. Gerber, J. G. Gimpel, D. P. Green, D. R. Shaw, Am. Polit Sci. Rev. 105, 135-150 (2011)

23. J. R. Zaller, The Nature and Origins of Mass Opinion (Cambridge Univ. Press, 1992).

24. D. Chong, J. N. Druckman, Annu. Rev. Polit. Sci. 10, 103-126 (2007).

25. S. J. Hill, J. Lo, L. Vavreck, J. Zaller, Polit. Commun. 30 , 521-547 (2013)

26. A. R. Todd, A. D. Galinsky, Soc. Personality Psychol. Compass 8, 374-387 (2014).

27. M. J. LaCour, D. P. Green, Science 346, 1366-1369 (2014).

28. M. McNutt, Science 348, 1100 (2015)

29. H. McGee, Personal route to reach public central to Yes campaign, Irish Times (14 May 2015); available at www.irishtimes.com/news/politics/personal-route-to-reach- public-central-to-yes-campaign-1.2211282 (accessed 25 Jan. 2016)

30. H. Han, How Organizations Develop Activists: Civic Associations and Leadership in the 21st Century (Oxford Univ. Press, 2014).

31. T. Skocpol, Diminished Democracy: From Membership to Management in American Civic Life (Univ. of Oklahoma Press 2003).

32. C. Panagopoulos, Party Polit. 22, 179-190 (2015).

\section{ACKNOWLEDGMENTS}

The authors acknowledge funding from the Gill Foundation for this research. D.B. acknowledges the National Science Foundation Graduate Research Fellowship Program for support while conducting this research. Replication data and code are available at http://dx.doi.org/10.7910/DVN/WKR39N. Neither of the authors is affiliated with the Los Angeles LGBT Center or SAVE or received compensation for this research. A preanalysis plan was filed after the data were collected but before they were analyzed with the treatment indicator, and revised preanalysis plans were also filed before the 3-week and 6-week surveys. These are available at the Evidence in Governance and Politics site (www. egap.org), ID 20150707AA. This research was approved by the University of California-Berkeley Committee for the Protection of Human Subjects, Protocol ID 2015-04-7508.

\section{SUPPLEMENTARY MATERIALS}

www.sciencemag.org/content/352/6282/220/suppl/DC1 Materials and Methods

Fig. S1

Tables S1 to S25

References (33-49)

30 November 2015; accepted 17 February 2016

$10.1126 /$ science.aad9713

\title{
Observational constraints on mixed-phase clouds imply higher climate sensitivity
}

\author{
Ivy Tan, ${ }^{1 *}$ Trude Storelvmo, ${ }^{1}$ Mark D. Zelinka ${ }^{2}$
}

Global climate model (GCM) estimates of the equilibrium global mean surface temperature response to a doubling of atmospheric $\mathrm{CO}_{2}$, measured by the equilibrium climate sensitivity (ECS), range from $2.0^{\circ}$ to $4.6^{\circ} \mathrm{C}$. Clouds are among the leading causes of this uncertainty. Here we show that the ECS can be up to $1.3^{\circ} \mathrm{C}$ higher in simulations where mixed-phase clouds consisting of ice crystals and supercooled liquid droplets are constrained by global satellite observations. The higher ECS estimates are directly linked to a weakened cloud-phase feedback arising from a decreased cloud glaciation rate in a warmer climate. We point out the need for realistic representations of the supercooled liquid fraction in mixed-phase clouds in GCMs, given the sensitivity of the ECS to the cloud-phase feedback.

M ixed-phase clouds, ubiquitous in Earth's atmosphere (1) at temperatures between $0^{\circ}$ and $-40^{\circ} \mathrm{C}$, strongly influence Earth's radiation budget (2-4). For a fixed amount of cloud water, spherical liquid droplets tend to be smaller in size (5) and also to outnumber ice crystals, because ice nuclei (IN) are relatively scarce in Earth's atmosphere in comparison to cloud condensation nuclei (6). As a consequence, clouds that consist of a higher fraction of liquid are optically thicker and hence more reflective of sunlight. Here we refer to the fraction of supercooled liquid within a mixedphase cloud at a particular isotherm as the supercooled liquid fraction (SLF).

It has recently been shown that SLFs are severely underestimated on a global scale in a multitude of global climate models (GCMs) $(7,8)$. This arises from two main causes. The first cause concerns the challenge of representing the microscopic nature of the various mixed-phase cloud

${ }^{1}$ Department of Geology and Geophysics, Yale University, New Haven, CT 06511, USA. ²Program for Climate Model Diagnosis and Intercomparison, Lawrence Livermore National Laboratory, Livermore, CA 94550, USA

*Corresponding author. E-mail: ivy.tan@yale.edu processes (9) that cannot be resolved at the typical spatial scales of GCMs. The Wegener-BergeronFindeisen (WBF) process for ice crystal growth is one such process that critically affects SLFs $(8,10-12)$. This process refers to the growth of ice crystals at the expense of surrounding supercooled liquid droplets in a mixed-phase cloud as a consequence of the lower saturation vapor pressure over ice relative to liquid. An ambient vapor pressure in between the saturation vapor pressures over liquid and ice is both a necessary and sufficient condition for the WBF process to occur in mixed-phase clouds (5). GCMs typically parameterize the WBF process by assuming homogeneous mixtures of supercooled liquid droplets and ice crystals within a model gridbox $(10,11)$. However, in situ observations suggest that such mixtures rarely exist in nature. Instead, pockets composed purely of either supercooled liquid droplets or ice crystals that are orders of magnitude smaller than the volume of a typical GCM gridbox are suggested to be the norm $(13,14)$. This implies that the WBF process may be too efficient in GCMs and is thus potentially a culprit for the underestimation of SLFs in GCMs. The multiple modes of ice nucleation (5), further complicated by the uncertainty associated with the efficiency 
This copy is for your personal, non-commercial use only.

If you wish to distribute this article to others, you can order high-quality copies for your colleagues, clients, or customers by clicking here.

Permission to republish or repurpose articles or portions of articles can be obtained by following the guidelines here.

The following resources related to this article are available online at www.sciencemag.org (this information is current as of April 7, 2016 ):

Updated information and services, including high-resolution figures, can be found in the online version of this article at:

/content/352/6282/220.full.html

Supporting Online Material can be found at:

/content/suppl/2016/04/07/352.6282.220.DC1.html

A list of selected additional articles on the Science Web sites related to this article can be found at:

/content/352/6282/220.full.html\#related

This article cites 34 articles, 10 of which can be accessed free:

/content/352/6282/220.full.html\#ref-list-1

This article has been cited by 1 articles hosted by HighWire Press; see:

/content/352/6282/220.full.html\#related-urls

This article appears in the following subject collections:

Psychology

/cgi/collection/psychology 